\title{
ERG rearrangement as a novel marker for predicting the extra-prostatic extension of clinically localised prostate cancer
}

\author{
LI LU* ${ }^{*}$, HAO ZHANG ${ }^{*}$, JUN PANG, GUO-LIANG HOU, MIN-HUA LU and XIN GAO \\ Department of Urology, Third Affiliated Hospital of Sun Yat-Sen University, Guangzhou, Guangdong 510630, P.R. China
}

Received December 4, 2014; Accepted January 13, 2016

DOI: $10.3892 / 01.2016 .4282$

\begin{abstract}
Currently, there are no well-established preoperative clinicopathological parameters for predicting extra-prostatic extension (EPE) in patients with clinically localised prostate cancer $(\mathrm{PCa})$. The transmembrane protease serine 2 (TMPRSS2)-ETS-related gene (ERG) fusion gene is a specific biomarker of $\mathrm{PCa}$ and is considered a prognostic predictor. The aim of the present study was to assess the value of this marker for predicting EPE in patients with clinically localised PCa. In total, $306 \mathrm{PCa}$ patients with clinically localised disease, including 220 patients $(71.9 \%)$ with organ-confined disease and $86 \mathrm{EPE}$ cases $(28.1 \%)$, were included in the study. Receiver operating characteristic curves and logistic regression were employed to establish the optimal cut-off value and to investigate whether $E R G$ rearrangement was an independent predictor for the EPE of clinically localised PCa. A leave-one-out cross-validation (LOOCV) model was implemented to validate the predictive power of ERG rearrangement. An increase in ERG rearrangements was identified to be associate'd with EPE, and the optimal cut-off for predicting EPE was determined to be $2.25 \%$, with a sensitivity of $70.24 \%$ [95\% confidence interval (CI), 62.6-78.9\%], a specificity of $80.43 \%$ (95\% CI, 75.4-85.1\%), and an area under the curve (AUC) of 0.781 (95\% CI, 0.730-0.826). In the LOOCV model, ERG rearrangement also demonstrated good performance for predicting EPE (sensitivity, 76.923\%; specificity, 71.429\%; 95\% CI for AUC, 0.724-0.958). In addition, a high Gleason score $(\geq 7)$ and a cT2c classification upon biopsy were independent factors for EPE.
\end{abstract}

\section{Introduction}

Prostate cancer $(\mathrm{PCa})$ is one of the most prevalent malignant tumours and is the second leading cause of cancer-associated

Correspondence to: Professor Xin Gao, Department of Urology, Third Affiliated Hospital of Sun Yat-Sen University, 600 Tianhe Road, Guangzhou, Guangdong 510630, P.R. China

E-mail: urologyzssy@126.com

*Contributed equally

Key words: extra-prostatic extension, ERG rearrangement, clinically localised prostate cancer, prediction mortality among men in Western countries (1). For men with localised PCa, radical prostatectomy (RP) is considered to be the ideal therapy; however, determining the optimal management strategy for locally advanced PCa remains a challenging issue (2). Traditionally, the malignant properties of PCa are characterised based predominantly on clinical stage, biopsy Gleason score (GS) and serum prostate-specific antigen (PSA) level, individually or collectively. These factors are helpful for guiding treatment decisions; however, they have limited predictive ability (3). Therefore, there is a critical need to develop novel prognostic predictors to improve clinical strategies for the treatment of PCa.

Extra-prostatic extension (EPE) is defined as the presence of cancer extending beyond the prostate gland, and it has long been considered an unfavourable prognostic factor in terms of cancer progression and survival (4-7). Identifying the presence of EPE is likely to reduce the chance of positive surgical margins; furthermore, it may be helpful for identifying patients who require postoperative adjuvant treatment. Traditionally, it has been difficult to assess patients who are at high risk for EPE based on a single preoperative clinicopathological variable or imaging information due to limited sensitivity (8-12). Hence, it is of practical significance to develop a new approach for predicting EPE.

Transmembrane protease serine 2 (TMPRSS2)-ETS-related gene $(E R G)$ is the most common gene fusion in $\mathrm{PCa}$; however, its prognostic value remains largely elusive (13-15). Our group has previously reported an initial scoring system for assessing $E R G$ rearrangements in biopsy samples, based on the use of fluorescence in situ hybridisation (FISH), for the diagnosis of PCa and the risk assessment of lymph node metastasis. This proposed system has demonstrated excellent sensitivity and specificity $(16,17)$. In clinical practice, an increase in $E R G$ rearrangements was observed to be associated with more aggressive characteristics. Thus, the aim of the current study was to explore the utility of ERG rearrangements and other preoperative parameters for predicting EPE in patients with clinically localised PCa.

\section{Materials and methods}

Patients and samples. This study included 409 consecutive patients who underwent RP at the Third Affiliated Hospital of Sun Yat-Sen University (Guangzhou, China) between January 2008 and June 2013. Of these patients, 103 without 
complete information prior to biopsy or with suspected metastasis by bone scan, computed tomography scan or magnetic resonance imaging (MRI) were excluded from the study. Finally, 306 cases with clinically localised PCa were enrolled in this retrospective analysis. The diagnosis of $\mathrm{PCa}$ was confirmed via transrectal ultrasound (TRUS)-guided needle biopsy preoperatively (median total biopsy cores, 12; range, 10-16). This study was approved by the Institutional Ethics Committee of the Third Affiliated Hospital of Sun Yat-Sen University, and all patients signed informed consent forms prior to the intervention.

Biopsies and corresponding prostatectomy specimens were retrospectively collected from 306 PCa patients for analysis. The selection of slides for FISH analysis was performed by the pathologist conducting the diagnosis. The $E R G$ rearrangement was calibrated with a dual-colour break-apart FISH assay (Beijing GP Medical Technologies, Ltd., Beijing, China) as previously described (16-18).

Pathological analysis. Morphological diagnoses were conducted according to the International Union Against Cancer 2009 staging classification guidelines for PCa (19), and histological analyses were performed according to the Gleason grading system (20). EPE was defined as the presence of any malignant cell beyond the prostatic capsule ( $\geq$ pT3a) according to the criteria described by Epstein (21), or the presence of pathologically confirmed positive lymph node metastasis.

Assessment of ERG rearrangements via FISH. FISH analysis was conducted according to the manufacturer's protocols (Beijing GP Medical Technologies, Ltd.) with certain modifications. Briefly, 3-mm tissue sections were obtained from tissue blocks and mounted on poly-L-lysine-coated slides (Beijing GP Medical Technologies, Ltd.). Following deparaffinisation, the tissue sections were dehydrated in 100,85 and 70\% ethanol for 2 min each. Subsequent to washing in deionised water for $5 \mathrm{~min}$, the sections were boiled in deionised water at $100^{\circ} \mathrm{C}$ for $27 \mathrm{~min}$ and then digested with Proteinase $\mathrm{K}$ (Beijing GP Medical Technologies, Ltd.) at $37^{\circ} \mathrm{C}$ for $10 \mathrm{~min}$. The sections on the slides were then dried, and hybridisation was performed as described previously $(16,17)$. Next, the slides were counterstained and mounted with DAPI, examined under an oil objective at 100x magnification using an Olympus fluorescence microscope (BX51; Olympus Corp., Tokyo, Japan) and imaged with a CCD camera (DP70; Olympus Corp.) using the PathFinder CellScan software system (IMSTAR S.A., Paris, France).

According to our scoring system, two yellow (red/green fusion) signals in a cell indicate a normal signal pattern, whereas the presence of one yellow/one green or one yellow/one green/one red signal in a cell commonly represents an abnormal signal pattern indicative of a partial deletion or translocation, respectively, of $E R G$.

During the evaluation of the FISH results, each slide was reviewed and $\geq 400$ epithelial cells were scored, with the strongest abnormal signals in the ' $z$ ' axis. ERG rearrangement rate in the patient was calculated using the following formula: ERG rearrangement rate $(\%)=$ number of cells exhibiting an abnormal signal pattern/number of cancer cells $(16,17)$. All slices were independently assessed by three experienced
Table I. Clinicopathological characteristics of the study sample $(n=306)$.

\begin{tabular}{|c|c|}
\hline Characteristic & Value \\
\hline Age, years; median (range) & $69(43-89)$ \\
\hline tPSA level, ng/ml; median (range) & $12.25(2.75-45.79)$ \\
\hline PV, ml; median (range) & $49(13-105)$ \\
\hline TBC, n; median (range) & $12(10-16)$ \\
\hline PBC, n; median (range) & $3(1-8)$ \\
\hline \multicolumn{2}{|l|}{ Clinical T classification, n (\%) } \\
\hline T1b-c & $63(20.6)$ \\
\hline $\mathrm{T} 2 \mathrm{a}$ & $112(36.6)$ \\
\hline $\mathrm{T} 2 \mathrm{~b}$ & $76(24.8)$ \\
\hline $\mathrm{T} 2 \mathrm{c}$ & $55(18.0)$ \\
\hline \multicolumn{2}{|l|}{ Biopsy GS, n (\%) } \\
\hline$\leq 6$ & $75(57.2)$ \\
\hline 7 & $81(26.5)$ \\
\hline$\geq 8$ & $50(16.3)$ \\
\hline \multicolumn{2}{|l|}{ Pathological TNM stage, n (\%) } \\
\hline $\mathrm{T} 2 \mathrm{a}$ & $56(18.3)$ \\
\hline $\mathrm{T} 2 \mathrm{~b}$ & $40(13.0)$ \\
\hline $\mathrm{T} 2 \mathrm{c}$ & $132(43.1)$ \\
\hline T3a & $39(12.7)$ \\
\hline $\mathrm{T} 3 \mathrm{~b}$ & $30(9.8)$ \\
\hline $\mathrm{T} 4$ & $9(2.9)$ \\
\hline \multicolumn{2}{|l|}{ Pathological GS, n (\%) } \\
\hline$\leq 6$ & $163(53.3)$ \\
\hline 7 & $79(25.8)$ \\
\hline$\geq 8$ & $64(20.9)$ \\
\hline \multicolumn{2}{|l|}{ Seminal vesicle invasion, $\mathrm{n}(\%)$} \\
\hline Negative & $265(86.8)$ \\
\hline Positive & $41(13.4)$ \\
\hline \multicolumn{2}{|l|}{ Lymph node metastasis, n (\%) } \\
\hline Negative & $280(91.5)$ \\
\hline Positive & $26(8.5)$ \\
\hline \multicolumn{2}{|l|}{ Capsule state, n (\%) } \\
\hline Organ-confined & $220(71.9)$ \\
\hline Extra-prostatic extension & $86(28.1)$ \\
\hline
\end{tabular}

PV, prostate volume; TBC, total biopsy cores; $\mathrm{PBC}$, positive biopsy cores; T, tumour; GS, Gleason score; TNM, tumour-node-metastasis.

researchers (Dr Li Lu, Dr Hao Zhang and Dr Guo-Liang Hou) who were blinded to the clinicopathological parameters, and any discordant results were reassessed until a consensus was achieved (Fig. 1A-F).

Statistical analysis. Clinicopathological parameters were analysed using the $\chi^{2}$ test or independent samples $t$-test (paired samples $t$-test for comparison between preoperative and postoperative ERG rearrangement rate, and independent samples $t$-test for comparison between EPE group and localised PCa group). Spearman's rank correlation coefficients were 
Table II. Comparison of clinicopathological features between the patients with and without EPE.

\begin{tabular}{|c|c|c|c|}
\hline Feature & Organ-confined & EPE & P-value \\
\hline Cases, n (\%) & $220(71.9)$ & $86(28.1)$ & \\
\hline Age, years; mean \pm SD & $68.64 \pm 7.668$ & $69.22 \pm 8.031$ & 0.558 \\
\hline tPSA level, ng/ml; mean \pm SD & $14.00 \pm 8.590$ & $18.05 \pm 11.774$ & 0.001 \\
\hline Prostate volume, $\mathrm{ml} ;$ mean $\pm \mathrm{SD}$ & $50.49 \pm 14.339$ & $51.43 \pm 13.938$ & 0.604 \\
\hline Percentage of $\mathrm{PBC}, \%$; mean $\pm \mathrm{SD}$ & $21.56 \pm 10.462$ & $36.41 \pm 10.680$ & $<0.0001$ \\
\hline Biopsy Gleason scores, n (\%) & & & $<0.0001$ \\
\hline$\leq 6$ & $151(86.3)$ & $24(13.7)$ & \\
\hline 7 & $56(69.1)$ & $25(30.9)$ & \\
\hline$\geq 8$ & $13(26.0)$ & $37(74.0)$ & \\
\hline Clinical TNM stage, n (\%) & & & $<0.0001$ \\
\hline $\mathrm{Tb}-1 \mathrm{c}$ & $47(74.6)$ & $16(25.4)$ & \\
\hline $\mathrm{T} 2 \mathrm{a}-\mathrm{T} 2 \mathrm{~b}$ & $160(85.1)$ & $28(14.9)$ & \\
\hline $\mathrm{T} 2 \mathrm{c}$ & $13(23.6)$ & $42(76.4)$ & \\
\hline
\end{tabular}

EPE, extra-prostatic extension; SD, standard deviation; tPSA, total prostate-specific antigen; PBC, positive biopsy cores; TNM, tumour-node-metastasis.

calculated to explore the relationship between $E R G$ rearrangement and clinicopathological outcome. Receiver operating characteristic (ROC) analysis and binary logistic regression were used to evaluate the predictive values of $E R G$ rearrangement and other variables for EPE. The 10-fold leave-one-out cross-validation (LOOCV) approach was used to validate the predictive performance of ERG rearrangement. Statistical analyses were performed using SPSS software version 13.0 (SPSS, Inc., Chicago, IL, USA) and MedCalc software version 12.7 (Medcalc Software, Ostend, Belgium). LOOCV analysis was performed in R 2.5.1 (http://cran.r-project.org). All tests were two-tailed, and $\mathrm{P}<0.05$ was considered to indicate statistical significance.

\section{Results}

Patient characteristics. The characteristics of the 306 patients are summarised in Table I. Pathological examination indicated that a total of 220 patients $(71.9 \%)$ had organ-confined disease, and $86(28.1 \%)$ showed evidence of EPE in the prostatectomy specimen (EPE group). No significant differences were observed in the comparison of mean $E R G$ rearrangements between biopsies and prostatectomy specimens $(\mathrm{P}=0.796)$ (Fig. 2A); however, the differences in $E R G$ rearrangements in the biopsy specimens were significant between the EPE group and the group with organ-confined disease $(\mathrm{P}<0.0001)$ (Fig. 2B).

Table II summarises the clinicopathological characteristics of the patients in the EPE group and the group with organ-confined disease. There was a significantly higher total PSA (tPSA) level $(\mathrm{P}=0.001)$ and a higher percentage of positive biopsy cores $(\mathrm{PBCs})$ in the EPE group $(\mathrm{P}<0.0001)$, and significant differences were also identified between the stratified biopsy GSs $(\leq 6,7$ and $\geq 8)$ and clinical $T$ classifications (T1b-T1c, T2a-T2b and T2c) $(\mathrm{P}<0.0001)$. However, there were no differences with regard to age $(\mathrm{P}=0.558)$ or prostate volume $(\mathrm{P}=0.604)$.
ERG rearrangement for predicting EPE. A significant positive association was identified between the $E R G$ rearrangement rate and pathological $\mathrm{T}$ classification $[\mathrm{r}=0.471 ; 95 \%$ confidence interval (CI), 0.379-0.554; $\mathrm{P}<0.0001$; Fig. 2C].

ROC analysis was used to explore the performance of $E R G$ rearrangement rates in the biopsy specimens for assessing the risk of EPE. ERG rearrangement was expressed as a continuous variable, and the results revealed that the area under the curve (AUC) was 0.781 (95\% CI, 0.730-0.826). An optimal cut-off value of $2.25 \%$ was established, with a sensitivity of $70.24 \%$ (95\% CI, 62.6-78.9\%) and a specificity of $80.43 \%$ (95\% CI, 75.4-85.1\%) (Fig. 2D).

To investigate the independent risk factors for the EPE of PCa, ERG rearrangement and other preoperative variables, including tPSA, biopsy GS and clinical T classification, were included in a logistic regression analysis, and the AUC of each parameter was compared. The results indicated that $E R G$ rearrangement had a better predictive value for EPE compared with tPSA (AUC, 0.599; 95\% CI, 0.541-0.654; $\mathrm{P}<0.0001)$; a slight, non-significant difference existed compared to clinical $\mathrm{T}$ classification (AUC, 0.715; 95\% CI, 0.660-0.765; $\mathrm{P}=0.094)$, and $E R G$ rearrangement had a similar predictive value to biopsy GS (AUC, 0.763; 95\% CI, 0.711-0.810; $\mathrm{P}=0.695$ ) (Fig. 2D).

Multivariate logistic regression models revealed that $E R G$ rearrangement in the biopsy sample was an independent predictor of EPE [odds ratio (OR), 1.997; 95\% CI, 1.277-3.124; $\mathrm{P}=0.002]$. In addition, biopsy $\mathrm{GSs}$ of 7 (OR, 2.669; 95\% CI, 1.116-6.383; $\mathrm{P}=0.027)$ and $\geq 8(\mathrm{OR}, 39.032$; 95\% CI, 10.397-146.527; $\mathrm{P}<0.0001)$, and a clinical T classification of T2c (OR, 9.103; 95\% CI, 3.338-24.824; P<0.0001) were independent predictors of EPE of clinically localised PCa. However, age, tPSA, prostate volume, number of PBCs, percentage of PBCs, biopsy GSs of $\leq 6$ and clinical T1b-1c and T2a-T2b staging were not independent risk factors for EPE (Table III). 

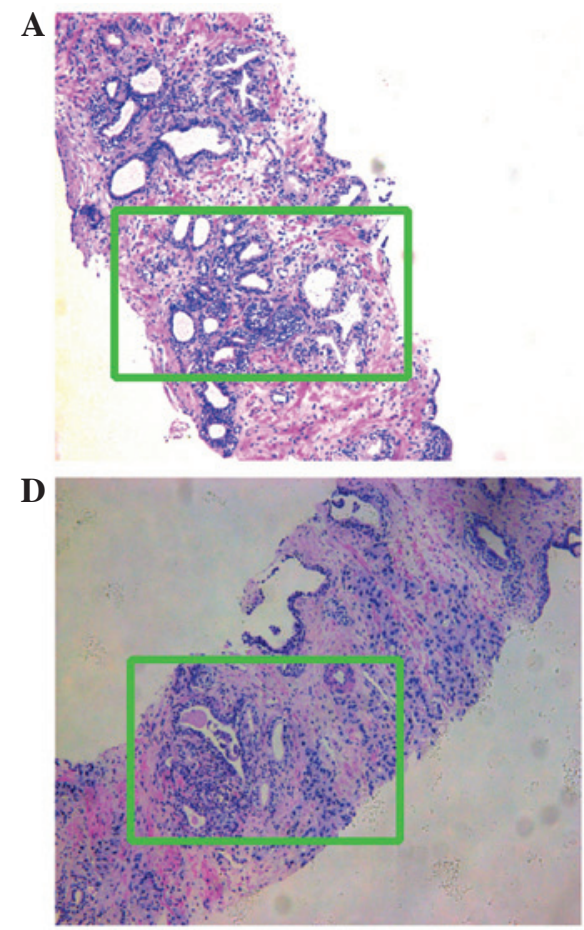

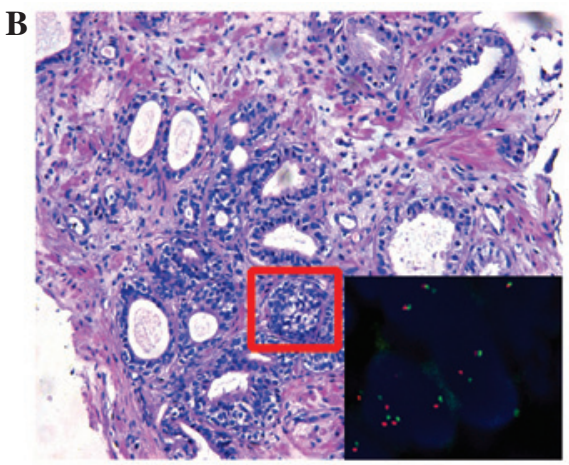

$\mathbf{E}$

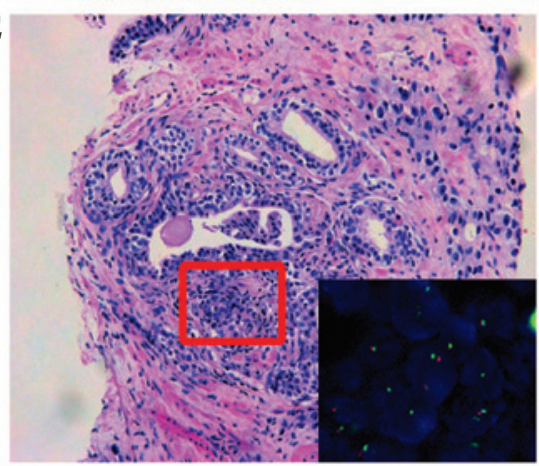

C

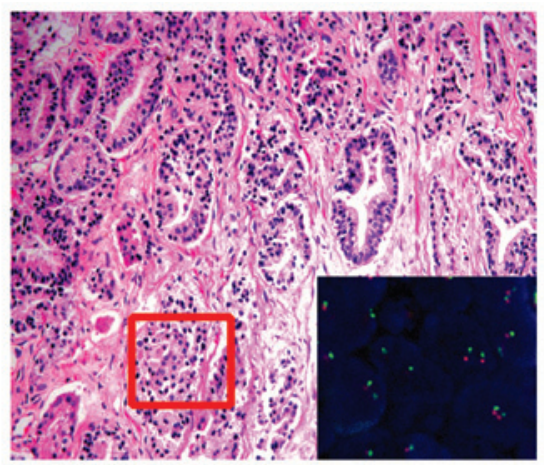

F

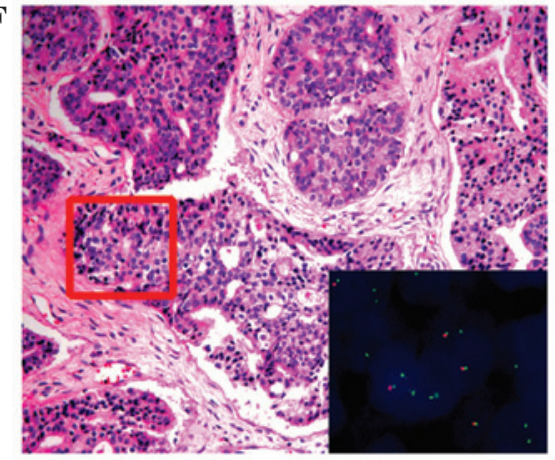

Figure 1. Hematoxylin and eosin staining and the corresponding fluorescence in situ hybridization images demonstrating $E R G$ rearrangements. (A) Prostatic biopsy tissue with prostate cancer glands (GS 3+4) (magnification, x100). (B) Image of the green boxed area in part A (magnification, x200); inset (lower right) shows $E R G$ probe image of the red boxed area in part $\mathrm{B}$ (magnification, $\mathrm{x} 1,000)$. (C) The corresponding prostatectomy tissue from part A with organ-confined disease (GS 3+4) (magnification, $\mathrm{x} 200$ ); inset (lower right) shows $E R G$ probe image of the red boxed area in part C (magnification, $\mathrm{x} 1,000$ ). (D) Prostatic biopsy tissue with prostate cancer glands (GS 3+4) (magnification, x100). (E) Image of the green boxed area in part D (magnification, x200); inset (lower right) shows $E R G$ probe image of the red boxed area in part $\mathrm{E}$ (magnification, $\mathrm{x} 1,000$ ). (F) The corresponding prostatectomy sample shown in part $\mathrm{D}$ with extra-prostatic extension, GS 4+4 (magnification, x200); inset (lower right) shows $E R G$ probe image of the red boxed area in part F, demonstrating an $E R G$ rearrangement (magnification, $\mathrm{x} 1,000)$. ERG, ETS-related gene; GS, Gleason score.
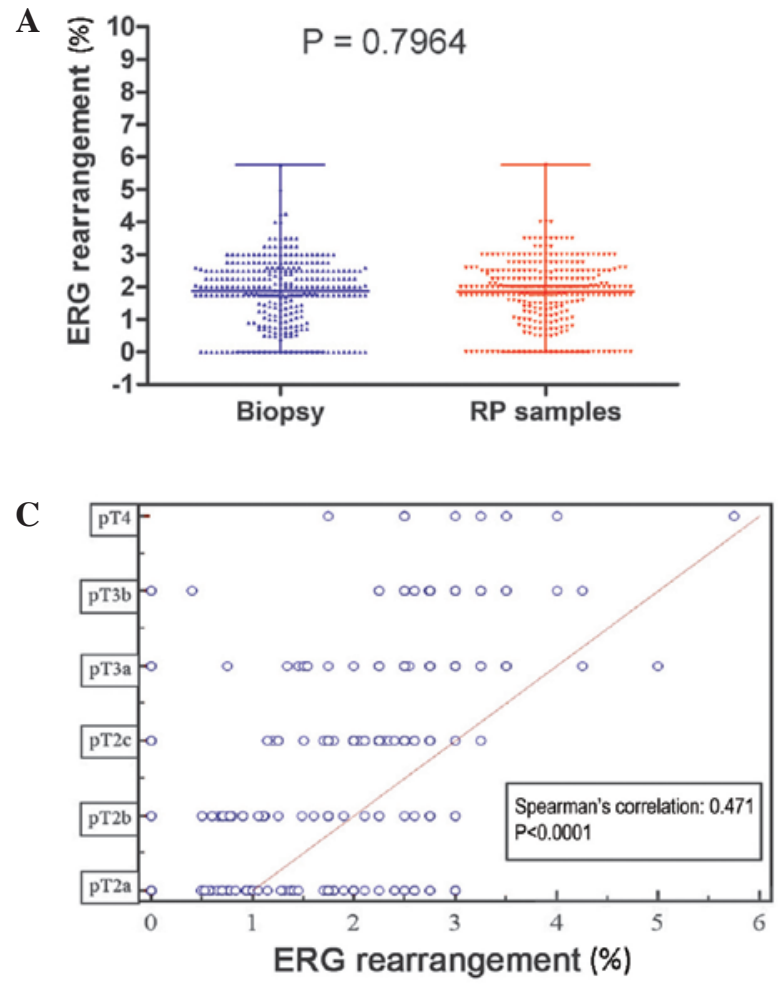
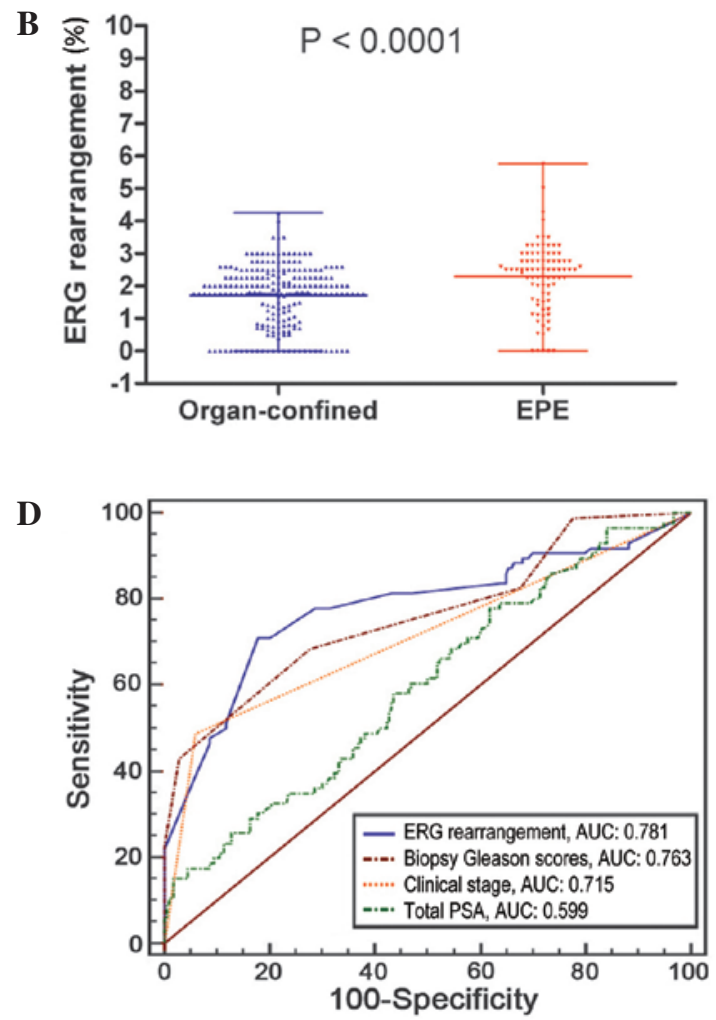

Figure 2. $E R G$ rearrangement as a predictor of EPE in prostate cancer. (A) $E R G$ rearrangement rates in biopsy and RP samples (P=0.796). (B) Comparison of $E R G$ rearrangements in biopsy specimens from the organ-confined group and EPE group $(\mathrm{P}<0.0001)$. (C) There was a significant association between the presence of $E R G$ rearrangement in the biopsy specimens and pathological stage $(\mathrm{r}=0.471, \mathrm{P}<0.0001)$. (D) Comparison of AUCs for $E R G$ rearrangement and other clinicopathological parameters. ERG, ETS-related gene; EPE, extra-prostatic extension; RP, radical prostatectomy; AUC, area under the curve; PSA, prostate-specific antigen. 
Table III. Multivariate logistic regression analysis of extra-prostatic extension prediction.

\begin{tabular}{lccr}
\hline Variable & Odds ratio & $95 \%$ CI & P-value \\
\hline Age & 0.992 & $0.945-1.041$ & 0.750 \\
tPSA level & 0.971 & $0.927-1.016$ & 0.203 \\
ERG rearrangement & 1.997 & $1.277-3.124$ & 0.002 \\
Prostate volume & 0.997 & $0.968-1.026$ & 0.966 \\
Number of PBCs & 1.956 & $0.449-8.525$ & 0.372 \\
Percentage of PBCs & 70.338 & - & 0.961 \\
Biopsy Gleason scores & & & - \\
$\leq 6$ & - & - & 0.027 \\
7 & 2.669 & $10.397-146.527$ & $<0.001$ \\
$\geq 8$ & 39.032 & & - \\
Clinical T classification & & - & $<0.001$ \\
T1b-T2b & - & $3.338-24.824$ & \\
T2c & 9.103 & &
\end{tabular}

$\mathrm{CI}$, confidence interval; tPSA, total prostate-specific antigen; ERG, ETS-related gene; PBC, positive biopsy core; T, tumour.

Table IV. 10-fold leave-one-out cross validation of ERG rearrangement for prediction of extra-prostatic extension.

\begin{tabular}{lcccc}
\hline No. & Sensitivity, $\%$ & Specificity, $\%$ & AUC & Cut-off (\%) \\
\hline 1 & 54.545 & 80.000 & 0.905 & 2.175 \\
2 & 62.750 & 73.684 & 0.780 & 2.450 \\
3 & 64.500 & 70.000 & 0.876 & 2.175 \\
4 & 63.636 & 68.421 & 0.854 & 2.450 \\
5 & 70.000 & 64.286 & 0.818 & 2.450 \\
6 & 76.923 & 71.429 & 0.776 & 2.450 \\
7 & 77.778 & 75.000 & 0.956 & 2.175 \\
8 & 90.000 & 70.000 & 0.824 & 2.450 \\
9 & 90.909 & 66.667 & 0.763 & 2.175 \\
10 & 92.857 & 62.500 & 0.868 & 2.175 \\
Total & 76.923 & 71.429 & $95 \%$ CI: $0.724-0.958$ &
\end{tabular}

$E R G$, ETS-related gene; AUC, area under the curve; CI, confidence interval.

Validation of the ability of ERG rearrangement to predict $E P E$. Ten-fold LOOCV was used to validate the power of $E R G$ rearrangement for predicting EPE. For all cases that were excluded from the model, a cut-off was assigned using 10-fold cross-validation, and a predictive value was determined for the excluded cases. In this LOOCV model, ERG rearrangement performed well for predicting EPE, with a sensitivity of $76.923 \%$ and a specificity of $71.429 \%$. The $95 \%$ CI for the AUC was 0.724-0.958. Thus, the null hypothesis of ROC $<0.5$ (random prediction) could not be rejected (Table IV).

\section{Discussion}

EPE is defined as the presence of cancer cells outside of the prostatic capsule (22). This terminology was introduced in 1996; subsequently, EPE was confirmed to be an adverse prognostic factor for PCa (22). Several variables, including the Partin table, MRI, TRUS and digital rectal examination findings, and prostate cancer antigen 3 score, have been studied to assess the predictive power of EPE; however, sensitivities have ranged from only $50-70 \%(8,9,23-25)$. Thus, there is an urgent need to explore novel and more effective approaches for predicting EPE for determining an appropriate surgical strategy and also for delineating a favourable postoperative adjuvant therapy.

The prostate-specific gene TMPRSS2 is fused with the transcription factor $E R G$ in a large proportion of cases of $\mathrm{PCa}$; however, its biological relationships with the clinicopathological parameters of the disease, such as PSA level, GS, pathological stage and prognosis, are not clear-cut, and the reported results lack consistency $(13-15,26)$. This may be due to differences in study design, detection techniques, 
sample origin and the intrinsic mechanism of gene rearrangement (27-29). In our pilot study, no significant association was identified between $E R G$ status and tumour stage in a limited cohort of patients (16). However, ERG rearrangement was found to be positively correlated with advanced tumour stage in a larger cohort of samples in this study, which is consistent with previous reports (28-31).

Overall, ERG rearrangement tends to be positively associated with advanced pathological stage, which has been further verified in a meta-analysis of 34 series (32). For example, Furusato et al (33) demonstrated that ERG protein expression is positively correlated with pathological stage, tumour grade and metastatic status in Japanese PCa patients. Paulo et al (34) also reported that a higher percentage of patients with locally advanced disease (pT3a) possess ERG rearrangements compared to patients with organ-confined disease. Minner et al (35) demonstrated that ERG fusion is positively associated with pathological stage, and $E R G$-positive patients tended to have higher GSs. The results of the present study revealed that $E R G$ rearrangement detection in biopsy specimens was positively correlated with advanced stage and was able to predict EPE, with an optimal cut-off of $2.25 \%$ and an AUC of 0.781 . In addition, $E R G$ rearrangement was an independent factor for EPE. In the LOOCV internal validation model, it was also observed that $E R G$ rearrangement was a valuable indicator of EPE, with a $95 \% \mathrm{CI}$ for the AUC ranging from 0.724 to 0.958 . The detection of $E R G$ rearrangements may be useful for guiding decisions related to surgical margins, regardless of the statuses of other clinicopathological factors.

In the present study, the clinical stage T2c was determined to be an independent predictor of EPE. The clinical T stage has long been considered an important factor for predicting EPE. For example, the use of a Partin table, including the clinical T stage, tPSA level and biopsy GS, was investigated for the prediction of EPE in 1997 (36). Subsequently, following several updates, other clinical variables were also incorporated into this model, thereby improving its predictive capacity $(3,37)$.

In the current study, it was also observed that biopsy GSs of 7 and $\geq 8$ were positively correlated with EPE, and a high GS was usually associated with advanced-stage PCa. The findings also demonstrated that ERG rearrangement had a similar AUC as biopsy GS (0.781 vs. 0.763); furthermore, multivariate logistic regression models revealed that biopsy GSs of 7 and $\geq 8$ were independent factors for EPE, which is consistent with prior publications $(12,38-40)$.

Other preoperative factors investigated in the present study, such as age, tPSA level, prostate volume and percentage of PBCs, were not found to have predictive power for EPE. Although previous studies have reported that these parameters may individually or collectively be used to predict EPE in $\mathrm{PCa}$ patients from Western countries (41), considering the discrepancies related to race and study population, it is necessary to further explore the predictive values of these parameters using a larger sample of Chinese patients with clinically localised PCa.

In summary, the current findings demonstrated that approximately $28.1 \%$ of patients with clinically localised PCa have EPE, and that ERG rearrangements in biopsy samples may be independent factors for predicting ECE, similar to biopsy GSs of $\geq 7$. These results may be useful for determining an appropriate surgical strategy in $\mathrm{PCa}$ patients with organ-confined disease. Consequently, the TMPRSS2-ERG gene, which is specific to PCa (18), should be studied further with regard to its roles in progression and prognosis, and may be a target for modern personalised therapy for PCa patients.

\section{Acknowledgements}

This work was supported by the Program of 5010 of Sun Yat-Sen University (grant no. 2007028 awarded to Professor Xin Gao). The authors are grateful to Professor Chun-kui Shao from the Department of Pathology at Third Affiliated Hospital of Sun Yat-Sen University.

\section{References}

1. Siegel R, Naishadham D and Jemal A: Cancer statistics, 2013. CA Cancer J Clin 63: 11-30, 2013.

2. Heidenreich A, Bellmunt J, Bolla M, Joniau S, Mason M, Matveev V, Mottet N, Schmid HP, van der Kwast T, Wiegel T and Zattoni F; European Association of Urology: EAU guidelines on prostate cancer. Part 1: Screening, diagnosis and treatment of clinically localised disease. Eur Urol 59: 61-71, 2011.

3. Eifler JB, Feng Z, Lin BM, Partin MT, Humphreys EB, Han M, Epstein JI, Walsh PC, Trock BJ and Partin AW: An updated prostate cancer staging nomogram (Partin tables) based on cases from 2006 to 2011. BJU Int 111: 22-29, 2013.

4. Hull GW, Rabbani F, Abbas F, Wheeler TM, Kattan MW and Scardino PT: Cancer control with radical prostatectomy alone in 1,000 consecutive patients. J Urol 167: 528-534, 2002.

5. Masieri L, Minervini A, Vittori G, Lanciotti M, Lanzi F, Lapini A, Carini M and Serni S: The role of free to total PSA ratio in prediction of extracapsular tumor extension and biochemical recurrence after radical prostatectomy in patients with PSA between 4 and $10 \mathrm{ng} / \mathrm{ml}$. Int Urol Nephrol 44: 1031-1038, 2012.

6. Magi-Galluzzi C, Evans AJ, Delahunt B, Epstein JI, Griffiths DF, van der Kwast TH, Montironi R, Wheeler TM, Srigley JR, Egevad LL and Humphrey PA; ISUP Prostate: International society of urological pathology (ISUP) consensus conference on handling and staging of radical prostatectomy specimens. Working group 3: Extraprostatic extension, lymphovascular invasion and locally advanced disease. Mod Pathol 24: 26-38, 2011.

7. van Veggel BA, van Oort IM, Witjes JA, Kiemeney LA and Hulsbergen-van de Kaa CA: Quantification of extraprostatic extension in prostate cancer: Different parameters correlated to biochemical recurrence after radical prostatectomy. Histopathology 59: 692-702, 2011.

8. Roethke MC, Lichy MP, Kniess M, Werner MK, Claussen CD, Stenzl A, Schlemmer HP and Schilling D: Accuracy of preoperative endorectal MRI in predicting extracapsular extension and influence on neurovascular bundle sparing in radical prostatectomy. World J Urol 31: 1111-1116, 2013.

9. Eisenberg ML, Cowan JE, Davies BJ, Carroll PR and Shinohara K: The importance of tumor palpability and transrectal ultrasonographic appearance in the contemporary clinical staging of prostate cancer. Urol Oncol 29: 171-176, 2011.

10. Schwartz DJ, Sengupta S, Hillman DW, Sargent DJ, Cheville JC, Wilson TM, Mynderse LA, Choo R and Davis BJ: Prediction of radial distance of extraprostatic extension from pretherapy factors. Int J Radiat Oncol Biol Phys 69: 411-418, 2007.

11. Brassell SA, Kao TC, Sun L and Moul JW: Prostate-specific antigen versus prostate-specific antigen density as predictor of tumor volume, margin status, pathologic stage and biochemical recurrence of prostate cancer. Urology 66: 1229-1233, 2005.

12. Magheli A, Rais-Bahrami S, Trock BJ, Humphreys EB, Partin AW, Han M and Gonzalgo ML: Prostate specific antigen versus prostate specific antigen density as a prognosticator of pathological characteristics and biochemical recurrence following radical prostatectomy. J Urol 179: 1780-1784, 1784; discussion, 2008.

13. Kumar-Sinha C, Tomlins SA and Chinnaiyan AM: Recurrent gene fusions in prostate cancer. Nat Rev Cancer 8: 497-511, 2008. 
14. Tomlins SA, Bjartell A, Chinnaiyan AM, Jenster G, Nam RK, Rubin MA and Schalken JA: ETS gene fusions in prostate cancer: From discovery to daily clinical practice. Eur Urol 56 : 275-286, 2009.

15. Clark JP and Cooper CS: ETS gene fusions in prostate cancer. Nat Rev Urol 6: 429-439, 2009.

16. Sun QP, Li LY, Chen Z, Pang J, Yang WJ, Zhou XF, Qiu JG, Su ZL, He D and Gao X: Detection of TMPRSS2-ETS fusions by a multiprobe fluorescence in situ hybridization assay for the early diagnosis of prostate cancer: A pilot study. J Mol Diagn 12: 718-724, 2010.

17. Gao X, Li LY, Zhou FJ, Xie KJ, Shao CK, Su ZL, Sun QP, Chen MK, Pang J, Zhou XF, et al: ERG rearrangement for predicting subsequent cancer diagnosis in high-grade prostatic intraepithelial neoplasia and lymph node metastasis. Clin Cancer Res 18: 4163-4172, 2012

18. Tomlins SA, Rhodes DR, Perner S, Dhanasekaran SM, Mehra R, Sun XW, Varambally S, Cao X, Tchinda J, Kuefer R, et al: Recurrent fusion of TMPRSS2 and ETS transcription factor genes in prostate cancer. Science 310: 644-648, 2005.

19. Sobin LH, Gospodarowicz MK and Wittekind C (eds): TNM Classification of Malignant Tumours, 7th edition. Wiley-Blackwell, Hoboken, NJ, 2010.

20. Epstein JI: An update of the Gleason grading system. J Urol 183: 433-440, 2010.

21. Epstein JI, Partin AW, Sauvageot J and Walsh PC: Prediction of progression following radical prostatectomy. A multivariate analysis of 721 men with long-term follow-up. Am J Surg Pathol 20: 286-292, 1996

22. Sakr WA, Wheeler TM, Blute M, Bodo M, Calle-Rodrigue R, Henson DE, Mostofi FK, Seiffert J, Wojno K and Zincke H: Staging and reporting of prostate cancer-sampling of the radical prostatectomy specimen. Cancer 78: 366-368, 1996.

23. Yu JB, Makarov DV, Sharma R, Peschel RE, Partin AW and Gross CP: Validation of the partin nomogram for prostate cancer in a national sample. J Urol 183: 105-111, 2010.

24. Karakiewicz PI, Bhojani N, Capitanio U, Reuther AM, Suardi N, Jeldres C, Pharand D, Péloquin F, Perrotte P, Shariat SF and Klein EA: External validation of the updated Partin tables in a cohort of North American men. J Urol 180: 898-902; discussion 902-903, 2008.

25. Pepe P, Fraggetta F, Galia A and Aragona F: Is PCA3 score useful in preoperative staging of a single microfocus of prostate cancer diagnosed at saturation biopsy? Urol Int 89: 143-147, 2012.

26. Xu B, Chevarie-Davis M, Chevalier S, Scarlata E, Zeizafoun N, Dragomir A, Tanguay S, Kassouf W, Aprikian A and Brimo F: The prognostic role of ERG immunopositivity in prostatic acinar adenocarcinoma: A study including 454 cases and review of the literature. Hum Pathol 45: 488-497, 2014.

27. Hermans KG, van Marion R, van Dekken $H$, Jenster G, van Weerden WM and Trapman J: TMPRSS2: ERG fusion by translocation or interstitial deletion is highly relevant in androgen-dependent prostate cancer, but is bypassed in late-stage androgen receptor-negative prostate cancer. Cancer Res 66: 10658-10663, 2006.

28. Perner S, Demichelis F, Beroukhim R, Schmidt FH, Mosquera JM, Setlur S, Tchinda J, Tomlins SA, Hofer MD, Pienta KG, et al: TMPRSS2: ERG fusion-associated deletions provide insight into the heterogeneity of prostate cancer. Cancer Res 66: 8337-8341, 2006.

29. Attard G, Clark J, Ambroisine L, Fisher G, Kovacs G, Flohr P, Berney D, Foster CS, Fletcher A, Gerald WL, et al: Duplication of the fusion of TMPRSS2 to ERG sequences identifies fatal human prostate cancer. Oncogene 27: 253-263, 2008.
30. Hofer MD, Kuefer R, Maier C, Herkommer K, Perner S, Demichelis F, Paiss T, Vogel W, Rubin MA and Hoegel J: Genome-wide linkage analysis of TMPRSS2-ERG fusion in familial prostate cancer. Cancer Res 69: 640-646, 2009.

31. Rajput AB, Miller MA, De Luca A, Boyd N, Leung S, Hurtado-Coll A, Fazli L, Jones EC, Palmer JB, Gleave ME, et al: Frequency of the TMPRSS2: ERG gene fusion is increased in moderate to poorly differentiated prostate cancers. J Clin Pathol 60: 1238-1243, 2007.

32. Pettersson A, Graff RE, Bauer SR, Pitt MJ, Lis RT, Stack EC, Martin NE, Kunz L, Penney KL, Ligon AH, et al: The TMPRSS2: ERG rearrangement, ERG expression and prostate cancer outcomes: A cohort study and meta-analysis. Cancer Epidemiol Biomarkers Prev 21: 1497-1509, 2012.

33. Furusato B, van Leenders GJ, Trapman J, Kimura T, Egawa S, Takahashi H, Furusato M, Visakorpi T and Hano $\mathrm{H}$ : Immunohistochemical ETS-related gene detection in a Japanese prostate cancer cohort: Diagnostic use in Japanese prostate cancer patients. Pathol Int 61: 409-414, 2011.

34. Paulo P, Barros-Silva JD, Ribeiro FR, Ramalho-Carvalho J, Jerónimo C, Henrique R, Lind GE, Skotheim RI, Lothe RA and Teixeira MR: FLI1 is a novel ETS transcription factor involved in gene fusions in prostate cancer. Genes Chromosomes Cancer 51: 240-249, 2012.

35. Minner S, Enodien M, Sirma H, Luebke AM, Krohn A, Mayer PS, Simon R, Tennstedt P, Müller J, Scholz L, et al: ERG status is unrelated to PSA recurrence in radically operated prostate cancer in the absence of antihormonal therapy. Clin Cancer Res 17: 5878-5888, 2011.

36. Partin AW, Kattan MW, Subong EN, Walsh PC, Wojno KJ, Oesterling JE, Scardino PT and Pearson JD: Combination of prostate-specific antigen, clinical stage and Gleason score to predict pathological stage of localized prostate cancer. A multi-institutional update. JAMA 277: 1445-1451, 1997.

37. Huang Y, Isharwal S, Haese A, Chun FK, Makarov DV, Feng Z, Han M, Humphreys E, Epstein JI, Partin AW and Veltri RW: Prediction of patient-specific risk and percentile cohort risk of pathological stage outcome using continuous prostate-specific antigen measurement, clinical stage and biopsy Gleason score. BJU Int 107: 1562-1569, 2011.

38. Paquette EL, Connelly RR, Sun L, Paquette LR and Moul JW: Predictors of extracapsular extension and positive margins in African American and white men. Urol Oncol 21: 33-38, 2003.

39. Nishimoto K, Nakashima J, Hashiguchi A, Kikuchi E, Miyajima A, Nakagawa K, Ohigashi T, Oya M and Murai M: Prediction of extraprostatic extension by prostate specific antigen velocity, endorectal MRI and biopsy Gleason score in clinically localized prostate cancer. Int J Urol 15: 520-523, 2008

40. Giannarini G, Scott CA, Moro U, Pertoldi B, Beltrami CA and Selli C: Are PSA density and PSA density of the transition zone more accurate than PSA in predicting the pathological stage of clinically localized prostate cancer?. Urol Oncol 26: 353-360, 2008

41. Lin S, Zhang Q, Li P, Li Z, Sun Y, Shao Y, Zhang X and Fu S: Prediction of extraprostatic extension in patients with clinically organ-confined prostate cancer. Urol Int 92: 282-8, 2014. 